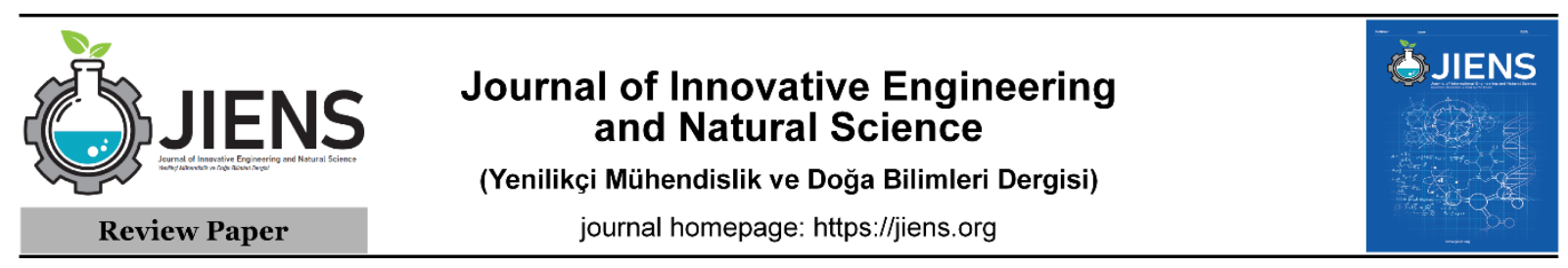

\title{
Hydroxyapatite Coatings on Magnesium Based Biomaterials
}

Serkan Başlayıc1 ${ }^{\mathrm{a}}$

${ }^{a}$ Istanbul Medipol University, Kavactk Mah. Ekinciler Cad. No:19, İstanbul 34810, Turkey.

ARTICLE INFO

Article history:

Received 21 May 2021

Received in revised form 15 June 2021

Accepted 25 June 2021

Available online

Keywords:

Magnesium alloys

Hydroxyapatite

Coating

Biomaterials

Bioactive

\begin{abstract}
Biomaterials can be coated with hydroxyapatite for different purpose. These reasons can be listed as increasing corrosion resistance, increasing biocompatibility, increasing adhesion to bone or tissue etc. Since the use of magnesium-based biomaterials is generally based on biodegradability properties, one of the main tasks of hydroxyapatite coating will be to increase corrosion resistance. In this study, hydroxyapatite coating methods on $\mathrm{Mg}$ based biomaterials and methods used to determine corrosion rate are mentioned. These methods are plasma spray coating, electrostatic coating, pulse electroplating, electrophoretic coating, sol-gel deposition, radio frequency magnetron sputtering. As a coating method, especially plasma spray coating is a promising method. The main reason for this is that there is no need for a secondary heat treatment after coating and that homogeneous coatings are obtained.
\end{abstract}

\section{INTRODUCTION}

Titanium alloys, Co-Cr alloys and stainless steels are metallic bio alloys that are prominent for hard tissue replacement applications and are frequently used due to their various properties. The mentioned properties can be listed as mechanical, corrosion resistance and biocompatibility. When these implants are used, a second surgical intervention is required to be removed from the body after recovery. The development of biodegradable implant materials for stents used in vessels and screws and plates used in hard tissues is in high demand by the biomedical market. The development of biodegradable materials applies not only to metallic, but also to polymers and bio ceramics. Only metallic biomaterials can simultaneously provide both the necessary mechanical properties and biodegradability for the applications listed above [1 - 4].

Traditional bio alloys are desired to be bio-inert and not to interact with surrounding tissues. Mg and its alloys are biodegradable. Because of its low corrosion resistance and dissolution in the body, $\mathrm{Mg}$ and its alloys have been considered insufficient as bio alloys for many years. However, the idea of using biodegradable implants as a result of increasing corrosion resistance by alloying and surface modification has been adopted and attracted attention by researchers in the last decade. In addition, as a result of the fact that the mechanical properties of Mg are very close to the bone and it has been demonstrated that it accelerates the bone healing process by about $30 \%$, the interest shown on it is increasing exponentially [5 - 9]. 
Hydroxyapatite is a material that is used for many different purposes and attracts attention in the biomedical field. Due to their excellent biocompatibility, osteoconductive properties and similarity to the inorganic component of human bones, they have uses such as bone fillings, bone tissue engineering scaffolds, bioactive coatings, soft tissue repairs, drug/protein/gene loading and delivery systems $[2,10,11]$.

Pure Hydroxyapatite is a stoichiometric apatite phase with a molar ratio of $1.67 \mathrm{Ca} / \mathrm{P}$, the most stable calcium phosphate salt at normal temperatures and $\mathrm{pH}$ between 4 and 12. It has the chemical formula $\mathrm{Ca}_{10}\left(\mathrm{PO}_{4}\right) \mathrm{OH}_{2}[12]$. Many studies have been carried out for years on the hydroxyapatite coating of traditional bio alloys such as stainless steels and Titanium alloys and some basic methods have been developed. However, not all these methods can be applied on $\mathrm{Mg}$, because the melting temperature of $\mathrm{Mg}$ is much lower than the other mentioned ones (316l $\sim 1400{ }^{\circ} \mathrm{C}, \mathrm{Ti}_{6} \mathrm{Al}_{4} \mathrm{~V} \sim 1660{ }^{\circ} \mathrm{C} \mathrm{Mg} \sim 650^{\circ} \mathrm{C}$ ). In addition to hydroxyapatite coating techniques applied to other bio alloys, there are techniques developed for coating magnesium only. The 6 most commonly used coating methods are: Electrophoretic Coating, Sol-Gel Deposition, Pulse Electroplating, Radio Frequency Magnetron Sputtering, Electrostatic Spray Coating, Plasma Spray Coating [1, 13].

\section{COATING METHODS}

\subsection{Electrophoretic Coating}

Conventional electrophoretic coating (EPD) is a 2-step process. The first step is to prepare the suspension containing the nano HA particles. In this process, Nano-HA particles are dissolved in a suitable liquid (isopropanol, methanol, acetic anhydride or ethanol). Then, carbon black is added to the mixture in the amount that only HA can be used. This suspension is then stirred for 24 hours on a magnetic stirrer and dispersed ultrasonically. It is then rested for one hour (for particles to collapse if only HA is used). As a second step, this suspension is placed in a cell. The bio alloy plate is attached to this cell as a cathode. A smaller plate of the same bio alloy is connected as the anode. Voltage is applied to this cell. Positively charged nano HA particles are collected to form a dense coating on the cathode. Before characterization, the coated cathode is subjected to another process. There are 4 commonly used methods for this process. 1) The coated sample is dried either in air at room temperature or in a humid stove at $60{ }^{\circ} \mathrm{C}$ for 24 hours. 2) The coated sample is dried and sintered. 3) The coated electrode is sintered for one hour at $800{ }^{\circ} \mathrm{C}$ or heated to $800{ }^{\circ} \mathrm{C}$ in a pre-degassed furnace, then kept in an argon atmosphere until the temperature reaches $1000{ }^{\circ} \mathrm{C}$, the samples are kept at $1000{ }^{\circ} \mathrm{C}$ for 1 hour and left to cool slowly in the furnace. The samples are removed after they reach room temperature (argon sintering) or removed at $800{ }^{\circ} \mathrm{C}$ in the degassed furnace and then heated to $1040{ }^{\circ} \mathrm{C}$ in vacuum. It is kept at $1040{ }^{\circ} \mathrm{C}$ for 1 hour. Then it is cooled in the oven. Then it is taken. (vacuum sintering). 4) It is dried at room temperature for 24 hours. It is sintered for 1.5 hours at $900{ }^{\circ} \mathrm{C}$ in an argon atmosphere. The coating on AZ91 samples is practically uncracked homogeneous and the surface roughness is good. (Supports adhesion and supports growth. Provides cell germination and high bone integration) Corrosion test results showed a significant decrease in corrosion rate. The coated samples showed a $90 \%$ reduction in corrosion rate compared to the uncoated samples. These results show that the coating effectively prevents corrosion $[14,15]$. 


\subsection{Sol-Gel Deposition}

It is a 2-stage process. Firstly, Sol-gel solution is prepared and mixed. Then the alloy is dipped vertically. It is rotated in the solution at a speed of $2000 \mathrm{rpm}$ and then the sample is taken out. In the 2nd step, the coated sample is kept at room temperature for 24 hours or dried in an oven at a temperature below $100{ }^{\circ} \mathrm{C}$. It is then sintered at a temperature suitable for the alloy. In this method, coating thickness, homogeneity and degree of crystallinity change depending on the sintering temperature $[5,6,14,15]$.

\subsection{Pulse Electroplating}

It is a 3-step process. First, the electrolyte is prepared. Electrolyte is a solution containing $\mathrm{Ca}\left(\mathrm{NO}_{3}\right)_{2}, \mathrm{NH}_{4} \mathrm{H}_{2} \mathrm{PO}_{4}$, and $\mathrm{H}_{2} \mathrm{O}_{2}$. The $\mathrm{pH}$ of the solution is brought to 4.5 and mixed at a speed of 400 cycles/minute until it becomes uniform. The mixture prepared in step 2 is taken into a cell where the implant cathode, platinum electrode anode and reference electrode are located. In the 3rd stage, the coating is made by providing a sudden voltage change with the help of a voltage generator [15].

\subsection{Radio Frequency Magnetron Sputtering}

With the help of Radiofrequency Magnetron source, the particles to be coated are sprayed onto the sample surface and coating is done. This process is carried out in an argon atmosphere and generally the radiofrequency is at the level of 500W [15].

\subsection{Electrostatic Spray Coating}

It is a method that can be applied in 2 different ways. In the first method, crystalline hydroxyapatite powders are sprayed onto the sample surface. These powders are subjected to electrostatic fields and make them charged. These charged particles follow the electric field lines and travel to the grounded alloy and begin to accumulate there. Therefore, hydroxyapatite is negatively charged, and the litter material is positively charged. The coated samples are then sintered in the Microwave oven. In the second method, the hydroxyapatite suspension is prepared in ethanol. The suspension is fed into the capillary tube via a peristaltic pump. Voltage is applied to the tube and grounded substrate material and the suspension is allowed to atomize. This directs the droplets onto the alloy surface and leaves a coating layer on the sample surface after the suspension evaporates. As a last step, the sample is washed with deionized water and dried at room temperature. Heat treatment can be applied to increase the bonding strength $[5,6,14,15]$. In figure 1 schematic representation of electrostatic spray coating is shown. 


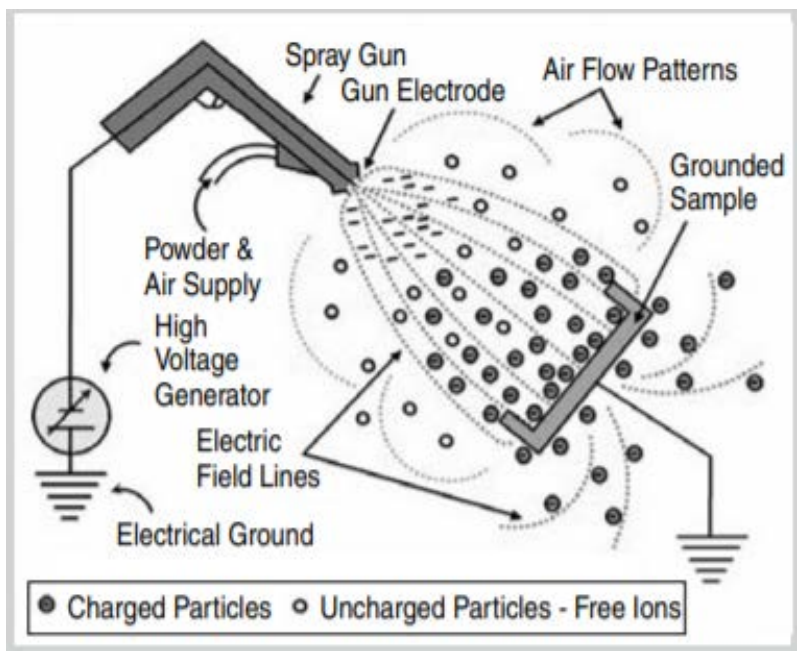

Figure 1. schematic representation of electrostatic spray coating [16]

\subsection{Plasma Spray Coating}

It is a very suitable method for covering implants used in orthopedic surgery, due to the ease of applying the procedure, high deposition rates, the fact that the litter material does not get too hot and is economically viable. It stands out as the most suitable method for coating metals with relatively low melting temperatures, such as Mg, since the temperature of the litter material does not rise too much. In the plasma spraying process, the coating is created by spraying molten or heat softened hydroxyapatite particles onto a metallic substrate. Typically, He, Ar, $\mathrm{N}_{2}, \mathrm{H}_{2}$ and a mixture of these gases are used as the plasma gas, while $\mathrm{Ar}$ is generally chosen as the main gas. Two main types of plasma are used for hydroxyapatite coating. Radio frequency (RF) and Direct current (DC). The plasma jet generated in the torch can heat the gas flowing between the electrodes to 6000-10,000 K. Compared to DC plasmas, RF plasma provides more homogeneous plasma temperature and particle velocity distributions, provides a higher purity coating due to the relatively non-contact processing to electrodes and results in a longer residence time of particles in the plasma as a result of lower plasma velocities. However, DC plasma has lower setup costs and is easy to use. In this coating process, only one surface of the sample can be covered. Therefore, the process must be applied again for other surfaces. Since the process cannot be done in a single step, different coating thickness can be observed on different surfaces [5, 6, 15, 17].

Table 1 shows the comparison of different coating methods in terms of some features. Coating thickness, advantages and disadvantages have been compared separately. Among these methods, plasma spray coating, electrostatic spray coating and dip coating methods similar to sol-gel coating were determined and applied as the methods to be applied within the scope of the thesis. The processing speed and ease of application of the plasma spray coating and electrostatic spray coating methods have been extremely important in these choices. In addition, electrophoretic coating has been applied many times in researches on Ti alloys and stainless steel, and plasma spray coating is recommended as a new trend. Although there are examples of electrophoretic coating on $\mathrm{Mg}$ alloys, the applications of plasma spray coating and electrostatic spray coating methods are extremely limited. However, in recent years, these 2 methods have emerged as promising methods [5, 6, 13-18]. 
The comparison of different coating methods is given in table 1. According to table 1, the most important coating method that stands out is seen as plasma spray coating. However, the need to apply the application repeatedly to the surfaces makes the process difficult. With electrostatic coating, it is possible to achieve coating thicknesses close to plasma spray, but the need for a secondary heat treatment makes the process difficult. The coating thicknesses made with Sol-gel are very thin, and the process steps and application are both complicated and longlasting [19].

Table 1. comparison of different coating methods

\begin{tabular}{|c|c|c|c|}
\hline Coating Method & $\begin{array}{l}\text { Coating } \\
\text { Thickness }\end{array}$ & Advantages & Disadvantages \\
\hline \multirow[b]{2}{*}{ Plasma Spray Coating } & \multirow[b]{2}{*}{$\sim 30-300 \mu \mathrm{m}$} & $\begin{array}{l}\text {-Thick layers can be coated at } \\
\text { high deposition rates. }\end{array}$ & $\begin{array}{l}\text { - Single surface } \\
\text { coating can be made. }\end{array}$ \\
\hline & & $\begin{array}{l}\text { - Increases biocompatibility, wear } \\
\text { and corrosion resistance. }\end{array}$ & $\begin{array}{l}\text {-Surface cracks may } \\
\text { occur due to rapid } \\
\text { cooling. }\end{array}$ \\
\hline \multirow{2}{*}{$\begin{array}{l}\text { Electrophoretic } \\
\text { Coating }\end{array}$} & \multirow{2}{*}{$\sim 0.1-2 \mathrm{~mm}$} & & $\begin{array}{l}\text { It is very difficult to } \\
\text { make a crack-free } \\
\text { coating. }\end{array}$ \\
\hline & & -Complex surfaces can be coated. & $\begin{array}{l}\text { Requires high } \\
\text { sintering temperature. }\end{array}$ \\
\hline \multirow[b]{2}{*}{ Sol-Gel Coating } & \multirow[b]{2}{*}{$<1 \mu \mathrm{m}$} & $\begin{array}{l}\text { - Complex surfaces can be } \\
\text { coated. }\end{array}$ & $\begin{array}{l}\text { - Requires atmospheric } \\
\text { control. }\end{array}$ \\
\hline & & $\begin{array}{l}\text {-Low processing temperature. } \\
\text { Thin film coating. }\end{array}$ & $\begin{array}{l}\text {-Raw materials are } \\
\text { quite expensive. }\end{array}$ \\
\hline \multirow[t]{2}{*}{$\begin{array}{l}\text { Electrostatic Spray } \\
\text { Coating }\end{array}$} & \multirow[t]{2}{*}{$\sim 1-200 \mu \mathrm{m}$} & -Ease of application & $\begin{array}{l}\text {-Uniform coating } \\
\text { thickness is very } \\
\text { difficult to obtain }\end{array}$ \\
\hline & & -High deposition rates & $\begin{array}{l}\text {-High Sintering } \\
\text { temperature }\end{array}$ \\
\hline
\end{tabular}

\section{CORROSION TESTS}

When biomaterials which are Mg based are used on the human body, they are generally used in an aqueous environment. For this reason, it is appropriate to apply corrosion tests applied in aqueous environments. There are 3 methods that can be applied when conducting corrosion studies on Mg alloys. These are weight loss method, Hydrogen collection and electrochemical methods. If it is desired to observe the passivation film and the phases formed on the surface of the material during the corrosion test, the electrochemical methods should be used. If it is desired to determine the material loss and corrosion rate due to corrosion in a long time, the weight loss method should be preferred. Especially in load-bearing parts such as screws and plates used in the skeleton system, it is extremely important to test the weight loss method in order to observe the changes in the surface and volume due to the long-term corrosion effect. However, the disadvantage of the weight loss method is that it takes an extremely long time. With the electrochemical methods, the corrosion rate data to be obtained in a few days can be reached in months with the weight loss method [20-24]. 
Potentiodynamic polarization (PDP), Potentiostatic polarization, Galvanostatic and Galvanodynamic polarization, Electrochemical impedance spectroscopy, Scanning vibrating electrode technique, Scanning electrochemical microscopy, Atomic emission spectroelectrochemistry methods can be considered as electrochemical methods [20]. PDP uses a reference electrode counter electrode and a potentiostat to scan the potential of an electrode at a constant speed over a fixed range. Potentiostat requirements for the PDP in recent years has led to the increasing importance of this method. This method works in the same way as potentiodynamic measurements, but here only one fixed potential is applied, and the current is measured. Potentiostatic polarization measurements can be useful when it is desired to investigate certain processes [20].

Galvanostatic polarization measurements are widely used for $\mathrm{Mg}$ based alloys. In electrochemical reactions, potential and current are interdependent. Therefore, it is possible to control one and measure the other. With the introduction of potentiostats, in most methods, the current is measured by applying it in a potential-controlled manner. Electrochemical impedance spectroscopy (EIS) method actually consists of measuring the response of an electrode to small-amplitude sinusoidal potential shaking at different frequencies [20].

The primary cathodic reaction in dissolution of $\mathrm{Mg}$ and its alloys in aqueous electrolytes is the reduction of water that causes the formation of hydrogen gas. It makes sense to collect hydrogen to determine the cathodic reaction rate. Unless there is an external influence, for the charge to be neutral, the anodic reaction rate must be equal to the cathodic reaction rate. $\left(\mathrm{i}_{\text {anod }}=\left|\mathrm{i}_{\text {cath }}\right|\right)$. Consequently, under open circuit conditions, it is possible to determine the instantaneous corrosion rate from the rate at which HE is formed at the electrode surface [20].

When applying the weight loss method, the samples are dipped into a container containing that solution or the solution is sprayed on the sample surface, in whatever environment it is desired to perform a corrosion test. Generally, dipping method is used for Mg alloys, while simulated body fluid is used as a corrosive medium [17, $20]$.

\section{CONCLUSIONS}

The use of magnesium and its alloys as biomaterials shows an increasing interest day by day. Surface modification is extremely important before these alloys are used as biomaterials. In this research, hydroxyapatite coating methods of magnesium alloys and corrosion tests used in determining the corrosion behavior afterwards were investigated.

Coating methods that do not require a secondary heat treatment, especially afterwards, have great advantages due to the low melting temperature of magnesium. Plasma spray coating stands out as the most affordable alternative.

Electrochemical methods should be used if it is desired to observe the corrosion zone and the formed phases while performing the corrosion test, and if the corrosion surface is to be observed for a long time, the weight loss method should be preferred. 


\section{REFERENCES}

[1] Hagihara K, Fujii K, Matsugaki A, Nakano T (2013) Possibility of Mg- and Ca-based intermetallic compounds as new biodegradable implant materials. Mater Sci Eng C 33(7):4101-4111. https://doi.org/10.1016/j.msec.2013.05.055

[2] Wen C, Guan S, Peng L, Ren C, Wang X, Hu Z (2009) Characterization and degradation behavior of AZ31 alloy surface modified by bone-like hydroxyapatite for implant applications. Appl Surf Sci 255(1314):6433-6438. https://doi.org/10.1016/j.apsusc.2008.09.078

[3] Watanabe T, Yamashita S, Hiraishi M (2001) Effect of surface treatment on the ultrasonic weldability of AZ31B magnesium alloy plate. Keikinzoku/Journal Japan Inst Light Met. https://doi.org/10.2464/jilm.51.521

[4] Vignesh RV, Padmanaban R, Govindaraju M (2020) Study on the corrosion and wear characteristics of magnesium alloy AZ91D in simulated body fluids. Bull Mater Sci. https://doi.org/10.1007/s12034-0191973-3.

[5] Bose S, Tarafder S, Bandyopadhyay A (2015) Hydroxyapatite coatings for metallic implants, vol. 7. Elsevier Ltd., 2015.

[6] Kannan MB (2015) Hydroxyapatite coating on biodegradable magnesium and magnesium-based alloys. In: Mucalo M (ed) Hydroxyapatite (HAp) Biomedical Applications, Woodhead Publishing, Sawston, pp 289-306. https://doi.org/10.1016/b978-1-78242-033-0.00013-4

[7] Hayakawa S (2015) In vitro degradation behavior of hydroxyapatite. Elsevier Ltd, Amsterdam.

[8] Staiger MP, Pietak AM, Huadmai J, Dias G (2006) Magnesium and its alloys as orthopedic biomaterials:A review. Biomaterials 27(9):1728-1734. https://doi.org/10.1016/j.biomaterials.2005.10.003

[9] Song G, Song S (2007) A possible biodegradable magnesium implant material. Adv Eng Mater 9(4):298302. 2007, https://doi.org/10.1002/adem.200600252

[10] Hahn BD et al. (2013) Effect of fluorine addition on the biological performance of hydroxyapatite coatings on Ti by aerosol deposition. J Biomater Appl 27(5):587-594. https://doi.org/10.1177/0885328211415723

[11] Chen XB, Birbilis N, Abbott TB (2011) A simple route towards a hydroxyapatite-Mg(OH)2 conversion coating for magnesium. Corros Sci 53(6):2263-2268. https://doi.org/10.1016/j.corsci.2011.03.008

[12] Kayali Y, Aslan O, Karabaş M, Ş. Talaş Ş (2016) Corrosion behaviour of single and double layer hydroxyapatite coatings on 316L stainless steel by plasma spray. Prot Met Phys Chem Surfaces 52(6):1079-1085. https://doi.org/10.1134/S2070205116060113

[13] Khalajabadi SZ, Abdul Kadir MR, Izman S, Ebrahimi-Kahrizsangi R (2015) Fabrication, bio-corrosion behavior and mechanical properties of a $\mathrm{Mg} / \mathrm{HA} / \mathrm{MgO}$ nanocomposite for biomedical applications. Mater Des 88:1223-1233. https://doi.org/10.1016/j.matdes.2015.09.065

[14] Rahman M, Li Y, Wen C (2020) HA coating on Mg alloys for biomedical applications: A review. J Magnes Alloy 8(3):929-943. https://doi.org/10.1016/j.jma.2020.05.003

[15] Lewis G (2017) Nanostructured Hydroxyapatite Coating on Bioalloy Substrates: Current Status and Future Directions. J Adv Nanomater 2(1):65-82. https://doi.org/10.22606/jan.2017.21007

[16] Liu H, Jiang W, Malshe A (2009) Coating for Dental and Orthopedic Implants. Jom 61(9):67-69.

[17] Baslayici S, Bugdayci M, Acma ME (2021) Corrosion behaviour of hydroxyapatite coatings on AZ31 and AZ91 magnesium alloys by plasma spray. J Ceram Process Res 22(1):98-105. https://doi.org/10.36410/jcpr.2021.22.1.98

[18] Galicia G, Pébère N, Tribollet B, Vivier V (2009) Local and global electrochemical impedances applied to the corrosion behaviour of an AZ91 magnesium alloy. Corros Sci 51(8):1789-1794. https://doi.org/10.1016/j.corsci.2009.05.005 
[19] Sun L, Berndt C, Gross KA, Kucuk A (2001) Material fundamentals and clinical performance of plasmasprayed hydroxyapatite coatings: A review. J Biomed Mater Res 58(5):570-592. https://doi.org/10.1002/jbm.1056

[20] Esmaily M et al. (2017). Fundamentals and advances in magnesium alloy corrosion. Prog Mater Sci 89:92193. https://doi.org/10.1016/j.pmatsci.2017.04.011

[21] Wang L., Shinohara T., Zhang BP (2010) Influence of chloride, sulfate and bicarbonate anions on the corrosion behavior of AZ31 magnesium alloy. J Alloys Compd. https://doi.org/10.1016/j.jallcom.2010.02.088.

[22] Wang L, Shinohara T, Zhang BP, Iwai H (2009) Characterization of surface products on AZ31 magnesium alloy in dilute $\mathrm{NaCl}$ solution. J Alloys Compd. https://doi.org/10.1016/j.jallcom.2009.06.071.

[23] Xin Y, Liu C, Huo K, Tang G, Tian X, Chu PK (2009) Corrosion behavior of ZrN/Zr coated biomedical AZ91 magnesium alloy. Surf Coatings Technol 203(17-18):2554-2557. https://doi.org/10.1016/j.surfcoat.2009.02.074

[24] Ballerini G, Bardi U, Bignucolo R, Ceraolo G (2005) About some corrosion mechanisms of AZ91D magnesium alloy. Corros Sci 47(9):2173-2184. https://doi.org/10.1016/j.corsci.2004.09.018 